\title{
Role of CB2 Cannabinoid Receptors in the Rewarding, Reinforcing, and Physical Effects of Nicotine
}

\author{
Francisco Navarrete 1,2, Marta Rodríguez-Ariass,3, Elena Martín-García ${ }^{2,4}$, Daniela Navarro', \\ María S García-Gutiérrez ${ }^{1,2}$, María A Aguilar ${ }^{2,3}$, Auxiliadora Aracil-Fernández ${ }^{1,2}$, Pere Berbel ${ }^{2,5}$, \\ José Miñarro $^{2,3}$, Rafael Maldonado ${ }^{2,4}$ and Jorge Manzanares*,1,2 \\ 'Instituto de Neurociencias, Universidad Miguel Hernández (UMH)-CSIC, Alicante, Spain; ${ }^{2}$ Red Temática de Investigación Cooperativa en Salud \\ (RETICS-Trastornos Adictivos), Instituto de Salud Carlos III, MICINN and FEDER, Madrid, Spain; ${ }^{3}$ Unidad de Investigación Psicobiología de las \\ Drogodependencias, Departamento de Psicobiología, Facultad de Psicología, Universitat de València, Valencia, Spain; ${ }^{4}$ Laboratori de \\ Neurofarmacologia, Departament de Ciéncies Experimentals i de la Salut, Universitat Pompeu Fabra, Barcelona, Spain; ${ }^{5}$ Departamento de \\ Histología y Anatomía, Universidad Miguel Hernández (UMH), Alicante, Spain
}

\begin{abstract}
This study was aimed to evaluate the involvement of CB2 cannabinoid receptors (CB2r) in the rewarding, reinforcing and motivational effects of nicotine. Conditioned place preference (CPP) and intravenous self-administration experiments were carried out in knockout mice lacking CB2r (CB2KO) and wild-type (WT) littermates treated with the CB2r antagonist AM630 (I and 3 mg/kg). Gene expression analyses of tyrosine hydroxylase $(\mathrm{TH})$ and $\alpha 3$ - and $\alpha 4$-nicotinic acetylcholine receptor subunits (nAChRs) in the ventral tegmental area (VTA) and immunohistochemical studies to elucidate whether CB2r colocalized with $\alpha 3$ - and $\alpha 4-n A C h R s$ in the nucleus accumbens and VTA were performed. Mecamylamine-precipitated withdrawal syndrome after chronic nicotine exposure was evaluated in CB2KO mice and WT mice treated with AM630 (I and $3 \mathrm{mg} / \mathrm{kg}$ ). CB2KO mice did not show nicotine-induced place conditioning and selfadministered significantly less nicotine. In addition, AM630 was able to block (3 mg/kg) nicotine-induced CPP and reduce (I and $3 \mathrm{mg} / \mathrm{kg})$ nicotine self-administration. Under baseline conditions, TH, $\alpha 3-n A C h R$, and $\alpha 4-n A C h R$ mRNA levels in the VTA of CB2KO mice were significantly lower compared with WT mice. Confocal microscopy images revealed that CB2r colocalized with $\alpha 3-$ and $\alpha 4-n A C h R s$. Somatic signs of nicotine withdrawal (rearings, groomings, scratches, teeth chattering, and body tremors) increased significantly in WT but were absent in CB2KO mice. Interestingly, the administration of AM630 blocked the nicotine withdrawal syndrome and failed to alter basal behavior in saline-treated WT mice. These results suggest that CB2r play a relevant role in the rewarding, reinforcing, and motivational effects of nicotine. Pharmacological manipulation of this receptor deserves further consideration as a potential new valuable target for the treatment of nicotine dependence.

Neuropsychopharmacology (20I3) 38, 25 I5-2524; doi:I0.1038/npp.2013.157; published online 24 July 2013
\end{abstract}

Keywords: nicotine; cannabinoid; conditioned place preference; self-administration; withdrawal; mice

\section{INTRODUCTION}

Tobacco consumption has been identified as a public health issue and one of the preventable causes of disease and death. Nicotine is the main psychoactive component of tobacco playing a major role in the development of dependence. Following cessation of chronic nicotine use, a withdrawal syndrome occurs including a cluster of symptoms such as irritability, tremors, bradycardia, and elevated anxiety. The withdrawal of nicotine promotes several neuroadaptive processes to counteract the negative state. Just as specific nicotinic acetylcholine receptor subunits (nAChRs) support the induction of nicotine addiction, other specific nAChRs

\footnotetext{
*Correspondence: Dr J Manzanares, Instituto de Neurociencias, Universidad Miguel Hernández (UMH)-CSIC, Avda. Ramón y Cajal s/n, 03550 San Juan de Alicante, Alicante, Spain, Tel: +34 96 5919248, Fax: +34965919561, E-mail: jmanzanares@umh.es

Received 6 February 2013; revised 18 June 2013; accepted 20 June 20।3; accepted article preview online 2 July 2013
}

underlie the withdrawal syndrome. For instance, $\alpha 3-, \alpha 5-$, and $\beta 4$-nAChRs are all found in the same gene cluster, and all of these subunits seem to help regulate consequences of nicotine withdrawal (Salas et al, 2004).

Nowadays, the most commonly used treatment for smoking cessation is the nicotine replacement therapy that partially relieves withdrawal symptoms and nicotine craving (Benowitz, 2010; Benowitz et al, 1993). Other approved smoking cessation therapies are bupropion, an atypical antidepressant acting as a noncompetitive antagonist of various nAChRs and inhibiting catecholamine reuptake (Dwoskin et al, 2006), and varenicline, an agonist on several nAChRs (Mihalak et al, 2006). The occurrence of serious side effects, including depression and suicidal behavior described in patients treated with bupropion or varenicline (Hays and Ebbert, 2010), justifies all the efforts to develop improved therapeutic approaches.

Although diverse psychopharmacological effects contribute to the overall process of nicotine addiction, the 
endocannabinoid system is emerging as a critical piece mediating the reinforcing effects of nicotine, as well as relapse to nicotine-seeking behavior. The characterization of the cross-talk between nicotine addiction and the endocannabinoid system is fundamental to understand the neurobiological mechanisms underlying nicotine dependence, although the available results are controversial. An acute dose of $\Delta^{9}$-THC reduced the incidence of precipitated nicotine withdrawal signs in mice (Balerio et al, 2004), whereas the coadministration of subthreshold doses of $\Delta^{9}$ THC and nicotine enhanced the somatic expression of nicotine withdrawal and nicotine-induced conditioned place preference (CPP) (Valjent et al, 2002). In addition, the CB1 cannabinoid receptor antagonist SR-141716A (rimonabant) reduced nicotine self-administration (Cohen et al, 2002), nicotine-induced CPP in rodents (Le Foll and Goldberg, 2004; Merritt et al, 2008), and nicotine-induced dopamine (DA) release in the nucleus accumbens (NAcc) (Cohen et al, 2002) and failed to precipitate withdrawal syndrome in nicotine-dependent mice (Castane et al, 2002). Moreover, CB1KO mice expressed neither nicotine-induced CPP (Castane et al, 2002) nor nicotine self-administration (Cossu et al, 2001), whereas no differences were found in nicotine withdrawal intensity between $\mathrm{CB} 1 \mathrm{KO}$ and wild-type (WT) mice (Castane et al, 2005; Castane et al, 2002; Cossu et al, 2001).

In the last years, significant contributions have demonstrated the potential involvement of the $\mathrm{CB} 2$ cannabinoid receptors (CB2r) in addiction. The first results showed increased CB2r gene expression in the brain of mice after chronic treatment with heroin or cocaine and decreased CB2r gene expression in striatum and ventral midbrain of mice after chronic ethanol intake (Onaivi et al, 2008a). In fact, mice that developed alcohol preference presented reduced $\mathrm{CB} 2 \mathrm{r}$ gene expression, and chronic treatment with JWH015, a CB2r agonist, enhanced alcohol consumption in stressed mice, whereas the administration of the CB2r antagonist AM630 reduced alcohol intake in stressed mice (Ishiguro et al, 2007). Recently, it has been reported that activation of CB2r inhibited cocaine self-administration, cocaine-enhanced locomotion, and cocaine-enhanced release of extracellular DA in the NAcc (Xi et al, 2011). Another study showed that activation of CB2r is involved in cocaine-induced reinstatement of cocaine-seeking behavior, although its activity is not necessary for the rewarding effects of cocaine (Adamczyk et al, 2012). In addition, latest results from our group suggest that overexpression of $\mathrm{CB} 2 \mathrm{r}$ (CB2xP mice) decreases cocaine motor responses and cocaine self-administration (Aracil-Fernandez et al, 2012).

The purpose of this study was to examine the role of CB2r on nicotine CPP, self-administration, and nicotine withdrawal syndrome in mice. Knockout mice lacking CB2r (CB2KO) and AM630-treated WT mice were used to study the rewarding effects of nicotine in the CPP, the nicotine reinforcing and motivational properties in self-administration, and the nicotine withdrawal syndrome. Specific changes in the gene expression of tyrosine hydroxylase (TH) and functional $\alpha 3$ - and $\alpha 4$-nAChRs in the ventral tegmental area (VTA) were measured by real-time PCR. The possibility of coexpression of CB2r with $\alpha 3$ - and $\alpha 4$-nAChRs in cell bodies and terminals of the mesolimbic DA system was evaluated by confocal microscopy.

\section{MATERIALS AND METHODS}

\section{Animals}

Homozygote male $\mathrm{CB} 2 \mathrm{KO}$ mice on a $\mathrm{CD} 1$ background ( $n=82$, for more details see Supplementary Information) and WT mice littermates $(n=198)$ were used in all experiments. Mice were 2- to 3-month old and weighed $25-35 \mathrm{~g}$ at the beginning of the experiments. Animals were maintained in a temperature-controlled $\left(23 \pm 2{ }^{\circ} \mathrm{C}\right)$ and humidity-controlled $(65 \pm 10 \%)$ room with a light-dark cycle (lights on 0800-2000 hours) except for the CPP and self-administration studies where a reversed light-dark cycle (lights off 0800-2000 hours) was used. All studies were conducted in compliance with the guidelines of the European Council Directive 2010/63/UE regulating animal research and approved by the local ethical committees.

\section{Drugs}

( - )-Nicotine hydrogen tartrate salt (Sigma, Madrid, Spain) was dissolved in physiological saline $(0.9 \% \mathrm{NaCl})$ and administered $0.5-1 \mathrm{mg} / \mathrm{kg}$ (i.p.; $0.3 \mathrm{ml}$ ), $0.03 \mathrm{mg} / \mathrm{kg}$ (i.v.; per infusion), or $25 \mathrm{mg} / \mathrm{kg} /$ day (s.c.; osmotic minipump). Mecamylamine hydrochloride (Sigma, Madrid, Spain) was dissolved in physiological saline and administered $2 \mathrm{mg} / \mathrm{kg}$ (s.c.; $0.3 \mathrm{ml}$ ). AM630 (Biogen, Madrid, Spain) was dissolved in a mixture of DMSO, Tween 80 , and distilled water $(1: 1: 8$ proportion) and administered $1-3 \mathrm{mg} / \mathrm{kg}$ (i.p.; $0.3 \mathrm{ml}$ ). For surgery procedures, ketamine hydrochloride $(100 \mathrm{mg} / \mathrm{kg})$ (Imalgène 1000; Rhône Mérieux, Lyon, France) and xylazine hydrochloride $(20 \mathrm{mg} / \mathrm{kg}$ ) (Sigma) were mixed and dissolved in ethanol (5\%) and distilled water (95\%) and administered (i.p.; $0.3 \mathrm{ml}$ ).

\section{Conditioned Place Preference}

Details of the apparatus and the procedure of nicotine CPP are described in the Supplementary Information.

\section{Intravenous Nicotine Self-Administration}

Nicotine self-administration sessions were performed in accordance to protocols previously described (Burokas et al, 2012; Martin-Garcia et al, 2009; Soria et al, 2008; Soria et al, 2005). Details of the apparatus, surgery, and the nicotine self-administration procedure are included in the Supplementary Information.

\section{Real-Time PCR Analyses}

$\mathrm{CB} 2 \mathrm{KO}$ and WT mice (basal conditions) were killed, and brains were removed from the skull and frozen over dry ice. Coronal brain sections $(500 \mu \mathrm{m})$ beginning at plates $19-20$ (Paxinos and Franklin, 2001) were obtained in a cryostat $\left(-10^{\circ} \mathrm{C}\right)$. The VTA was microdissected according to a modification of the Palkovits method (Palkovits, 1983) as previously described (Navarrete et al, 2012). Total RNA was isolated from brain tissue micropunches using Trizol reagent (Invitrogen, Madrid, Spain) and subsequently retrotranscribed to cDNA. Quantitative analysis of the relative abundance of TH (Mm00447546_m1), $\alpha 3$-nAChRs (Mm00520145_m1), and $\alpha 4-\mathrm{nAChRs} \mathrm{(Mm00516561 \_ m1)}$ 
gene expressions was performed on the StepOne Sequence Detector System (Life Technologies, Madrid, Spain). The reference gene used was 18S rRNA (Hs99999901_s1). Relative mRNA abundance was determined using the $2^{-\Delta \Delta C \mathrm{t}}$ method (Livak and Schmittgen, 2001).

\section{Inmunohistochemistry}

Floating coronal sections from WT mice containing NAcc and VTA (for more details see Supplementary Information) were incubated in parallel with goat anti-CB2r $(1: 250$, Santa Cruz Biotechnology) combined with either rabbit anti- $\alpha 3$ nAChRs (1:25, Santa Cruz Biotechnology) or monoclonal mouse anti- $\alpha 4$-nAChRs ( $1: 250$, Santa Cruz Biotechnology). All sections were then incubated with monkey biotinylated anti-goat antibody (1:800, Vector, Burlingame, CA) and avidin-BODIPY FL $(1 \mu \mathrm{g} / \mathrm{ml}$, Molecular Probes, Eugene, $\mathrm{OR})$ (CB2r, green) and with goat rhodamine red-X anti-rabbit ( $\alpha 3$-nAChRs, red) or horse rhodamine red-X anti-mouse ( $\alpha 4$-nAChRs, red) (1:150, Molecular Probes). Fluorescent sections were mounted using ProLong Gold (Molecular Probes), studied by a Leica confocal laser fluorescence microscope, and processed using the LCS Lite software. CB2r antibody specificity was assessed with conventional immunohistochemistry (Supplementary Information and Supplementary Figure 1).

\section{Nicotine Treatment and Withdrawal}

Nicotine dependence was induced by using Alzet osmotic minipumps (Model 2002; Alzet, Cupertino, California). These minipumps, implanted subcutaneously under ketamine/xylazine mixture anesthesia, contained saline or nicotine solutions and delivered a constant subcutaneous flow in a rate of $0.5 \mu \mathrm{l} / \mathrm{h}$ during the whole experimental sequence. Animals received a dose of nicotine of approximately $25 \mathrm{mg} / \mathrm{kg} /$ day. Nicotine withdrawal syndrome was precipitated 14 days after minipump implantation by injection of the nicotinic receptor antagonist mecamylamine ( $2 \mathrm{mg} / \mathrm{kg}$; s.c.). Genetic (CB2KO mice) and pharmacological (AM630 administration) approaches were used in this set of experiments. For the pharmacological studies, mice received a systemic ( 1 and $3 \mathrm{mg} / \mathrm{kg}$; i.p.) injection of AM630 $30 \mathrm{~min}$ before mecamylamine-precipitated nicotine withdrawal syndrome. The somatic signs of withdrawal were evaluated immediately after mecamylamine injection for $25 \mathrm{~min}$, in which animals were introduced in an openfield arena. Rearings, groomings, scratches, teeth chattering, and body tremors were counted.

\section{Statistical Analyses}

Statistical analyses were performed using Student's $t$-test when comparing two groups and one-, two-, or three-way analyses of variance (ANOVA) when comparing three or more groups. When appropriate, post-hoc individual differences between groups were determined using the Student-Newman-Keuls test. Specific statistical analyses are described in Supplementary Information. Differences were considered significant when $P<0.05$. SigmaStat version 3.11 and SPSS version 17 software were used.

\section{RESULTS}

\section{Nicotine CPP}

The ANOVA of the data from the CPP procedure (Figure 1a) revealed a significant effect of the variable days $\left(\mathrm{F}_{1,58}=\right.$ $6.021, P<0.01)$, as more time was spent in the drug-paired compartment in the Post-C test than in the Pre-C $(P<0.01)$. The interaction days $\times$ genetics also showed an effect $\left(\mathrm{F}_{1,58}=3.253, \quad P<0.05\right)$, as only WT mice developed nicotine-induced CPP $(P<0.01)$ for the doses of 1 and $0.7 \mathrm{mg} / \mathrm{kg}$. No preference was obtained in CB2KO mice.

\section{Effect of AM630 on Nicotine CPP}

The ANOVA of the effect of AM630 on the nicotine-induced CPP (Figure 1b) revealed a significant effect of the interaction days $\times$ nicotine dose $\left(\mathrm{F}_{1,57}=12.174, P<0.001\right)$ and days $\times$ AM630 $\left(F_{1,57}=3.338, P<0.05\right)$. More time was spent in the drug-paired compartment in the Post-C test than in the Pre-C only in those groups receiving nicotine $(P<0.01)$. This effect was due to the groups conditioned with nicotine alone $(P<0.01)$ or plus $1 \mathrm{mg} / \mathrm{kg}$ of AM630 $(P<0.001)$. In addition, the group conditioned only with

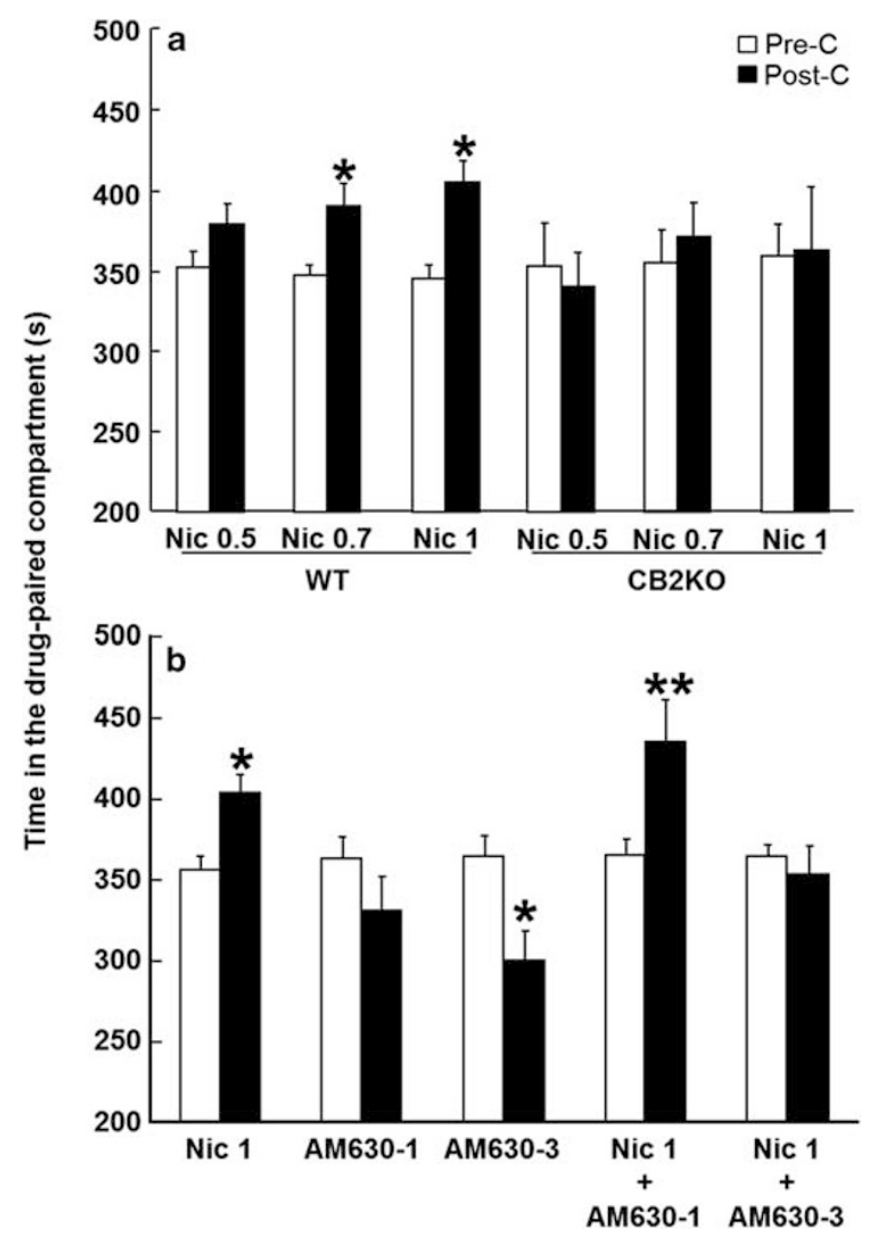

Figure I Nicotine-induced CPP in CB2KO and WT mice and effects of AM630. ( $a$ and b) The bars represent the time spent in seconds in the drug-paired compartment during the preconditioning test and the postconditioning test. $* P<0.01$, **P $>0.01$, significant difference in the time spent in the drug-paired compartment in preconditioning vs postconditioning tests. 
$3 \mathrm{mg} / \mathrm{kg}$ of AM630 developed aversion to the compartment associated with this $\mathrm{CB} 2 \mathrm{r}$ antagonist $(P<0.01)$. No CPP was observed in the group conditioned with $1 \mathrm{mg} / \mathrm{kg}$ of nicotine plus $3 \mathrm{mg} / \mathrm{kg}$ of AM630.

\section{Acquisition and Maintenance of Nicotine Self- Administration in CB2KO and WT Mice}

Two-way ANOVA of the number of infusions during the 10 days of self-administration revealed significant main effects of genotype $\left(\mathrm{F}_{1,28}=77.23, P<0.001\right)$, day $\left(\mathrm{F}_{9,252}=4.74\right.$, $P<0.001)$, and interaction between genotype and day $\left(\mathrm{F}_{9,252}=5.50, P<0.001\right)$. The number of infusions was

Table I Operant Responding Maintained by Nicotine During Acquisition

\begin{tabular}{lll}
\hline & \multicolumn{2}{c}{ Three-way ANOVA } \\
\cline { 2 - 3 } & \multicolumn{2}{c}{ Acquisition FR I } \\
\cline { 2 - 3 } & F-value & $P$-value \\
\hline Genotype & $F_{(1,28)}=58.33$ & $P<0.001$ \\
Hole & $F_{(1,28)}=58.40$ & $P<0.001$ \\
Day & $F_{(9,252)}=6.79$ & $P<0.001$ \\
Hole $\times$ day & $F_{(9,252)}=9.17$ & $P<0.001$ \\
Genotype $\times$ hole & $F_{(1,28)}=49.01$ & $P<0.001$ \\
Genotype $\times$ day & $F_{(9,252)}=2.04$ & $P<0.05$ \\
Genotype $\times$ hole $\times$ day & $F_{(9,252)}=5.95$ & $P<0.001$ \\
\hline
\end{tabular}

significantly lower in CB2KO than in WT mice. On FR1 schedule, the acquisition criteria of the operant responding maintained by nicotine $(0.03 \mathrm{mg} / \mathrm{kg} /$ infusion $)$ were achieved by $90 \%$ of WT and $0 \%$ of CB2KO mice. Active nose-poking responses were significantly lower in $\mathrm{CB} 2 \mathrm{KO}$ than in WT mice (see Table 1 for three-way ANOVA). Only WT mice discriminated between the active and the inactive holes during most of the whole period of training, except the first day, and the number of active nose-poking responses increased across days, whereas the inactive nose-poking responses decreased over time (Figure 2a). The mean number of active nose poking for nicotine reinforcement during the last 3 days of FR1 was $11.94 \pm 1.50$ in WT and $2.84 \pm 0.45$ in CB2KO.

In the PR schedule of reinforcement, the breaking point values were significantly decreased in $\mathrm{CB} 2 \mathrm{KO}$ mice when compared with WT littermates $\left(F_{1,28}=27.63, P<0.001\right)$, revealing a reduction in the motivation for nicotine in $\mathrm{CB} 2 \mathrm{KO}$ mice (Figure $2 \mathrm{~b}$ ).

\section{Pharmacological Regulation of Nicotine Self- Administration with AM630}

WT mice were trained to self-administer nicotine during 7 days to evaluate the effects of AM630 on the regulation of the reinforcing effects of nicotine during self-administration $(0.03 \mathrm{mg} / \mathrm{kg} /$ infusion $)$. One-way ANOVA of the number of infusions during the 7 days of self-administration training revealed significant main day effects $\left(\mathrm{F}_{6,120}=2.83, P<0.05\right)$. The acquisition criteria of the operant responding maintained by nicotine were achieved by $92 \%$ of mice. Two-way ANOVA revealed that mice discriminated between the
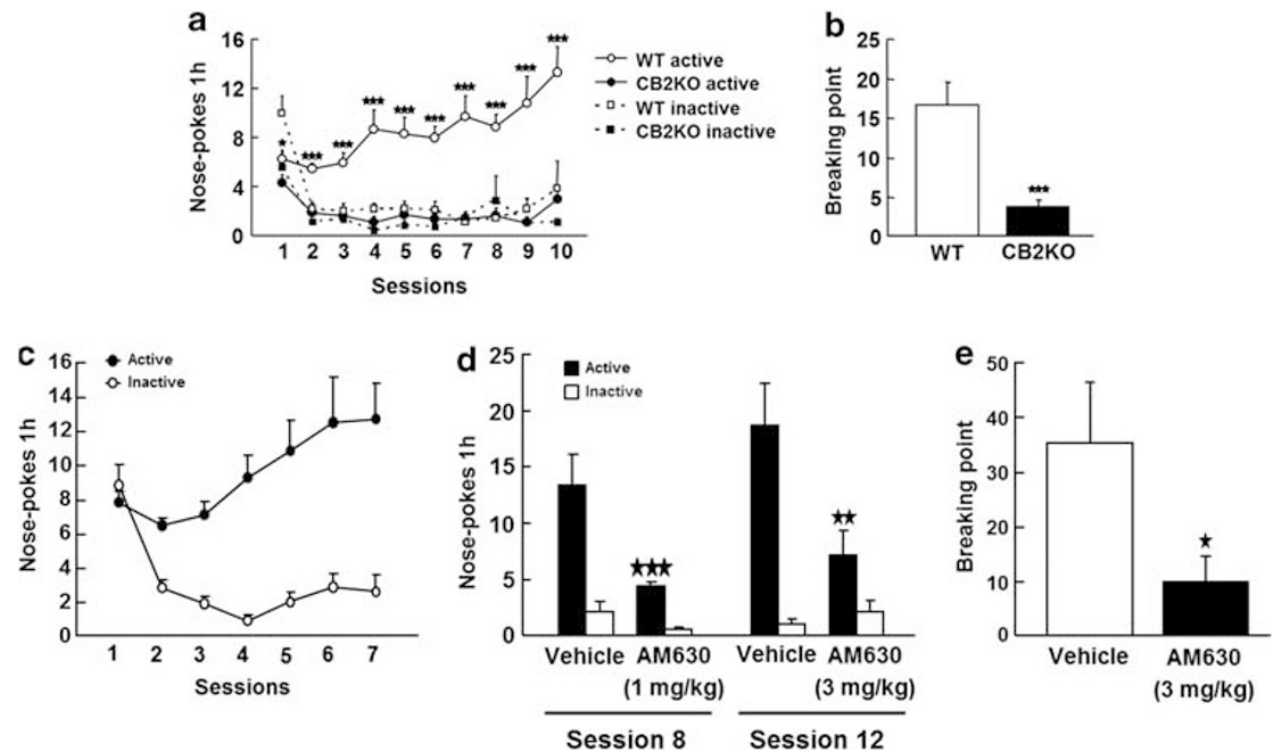

Figure 2 Acquisition of nicotine self-administration and motivation for nicotine in CB2KO and WT mice and effects of AM630. (a) Mean number of active and inactive nose pokes during FRI schedule of reinforcement to obtain nicotine at the dose of $0.03 \mathrm{mg} / \mathrm{kg} / \mathrm{infusion}$ i.v. in I-h daily sessions during 10 days; (b) mean breaking point in a session of progressive ratio that was conducted once and lasted $3 \mathrm{~h}$ for WT and CB2KO mice; (c) mean number of active and inactive nose pokes in WT mice during FR I schedule of reinforcement to obtain nicotine at the dose of $0.03 \mathrm{mg} / \mathrm{kg} / \mathrm{infusion}$ i.v. in I-h daily sessions during 7 days; (d) after acquisition, the administration of AM630 (I and $3 \mathrm{mg} / \mathrm{kg}$, i.p.) decreased the number of responses in the active hole when tested on day 8 and day 12, respectively; and (e) mean breaking point in a session of progressive ratio that was conducted on day 15 and lasted $3 \mathrm{~h}$ for mice administered with vehicle or AM630 (3 mg/kg, i.p.). The number of mice was 12 for the WT group and 18 for the KO group in panels a and b. The total number of subjects was 21 in panel c. The number of mice was 7 for the vehicle group and 14 for the AM630 group in panels $d$ and e. Data are expressed as mean \pm SEM. $* P<0.05$, ** $P<0.01$, *** $P<0.00$ I comparison between groups (the Student-Newman-Keuls test or one-way ANOVA). 
active and the inactive holes $\left(\mathrm{F}_{1,120}=39.59, P<0.01\right)$ during the whole period of training, excepting the first day. The evolution across days was significant $\left(\mathrm{F}_{6,120}=2.95\right.$, $P<0.05)$, showing an increase across days of the number of active nose-poking responses, whereas the inactive nosepoking responses decreased over time as revealed by the significant interaction between days and hole $\left(\mathrm{F}_{6,120}=6.04\right.$, $P<0.001)$. The mean number of active nose poking during the last 3 days of FR1 acquisition (sessions 5-7) was $11.91 \pm 1.90$ (Figure 2c). After acquisition, mice were assigned to two different homogeneous groups as revealed by two-way ANOVA. Indeed, no significant differences on active or inactive nose poking were revealed between these two groups $\left(\mathrm{F}_{2,18}=0.26\right.$, NS) during the 7 days of selfadministration training. After acquisition, the administration of AM630 (1 and $3 \mathrm{mg} / \mathrm{kg}$, i.p.) decreased the number of responses in the active hole when tested on day $8(P<0.001)$ and day $12(P<0.01)$, respectively (see Table 2 for two-way ANOVA and Figure 2d). In the PR schedule of reinforcement, the breaking point values were significantly decreased in mice receiving AM630 (3 mg/kg, i.p.) compared with mice treated with vehicle $\left(\mathrm{F}_{1,19}=4.78, P<0.05\right)$, revealing a reduction in the motivation for nicotine (Figure 2e). Additionally, one-way repeated measures ANOVA in active nose pokes from session 7 to session 14 of mice injected with AM630 were performed to evaluate the effects of different doses on nose-poking responses and the recovery of basal levels after each injection. Results revealed significant effects of session $\left(\mathrm{F}_{7,91}=4.93, P<0.001\right)$, and post-hoc analyses (the Student-Newman-Keuls test) showed decreased active nose-poking response on session 8 when injected with AM630 ( $1 \mathrm{mg} / \mathrm{kg}$, i.p.) compared with session $7(P<0.01)$. The recovery to basal levels was then observed on sessions $10 \quad(P<0.05)$ and $11 \quad(P<0.01)$. Subsequently, active nose poking decreased again on session 12 when injected with AM630 (3 mg/kg, i.p.)

Table 2 Pharmacological Regulation of Nicotine SelfAdministration with AM630

\begin{tabular}{|c|c|c|c|c|}
\hline & \multirow{2}{*}{\multicolumn{2}{|c|}{$\begin{array}{c}\text { Two-way ANOVA } \\
\text { Session } 8 \text { FRI }\end{array}$}} & \multirow{2}{*}{\multicolumn{2}{|c|}{$\begin{array}{c}\text { Two-way ANOVA } \\
\text { Session I2 FRI }\end{array}$}} \\
\hline & & & & \\
\hline & F-value & $P$-value & F-value & $P$-value \\
\hline Group & $F_{(1,19)}=11.77$ & $P<0.01$ & $F_{(1,19)}=5.25$ & $P<0.05$ \\
\hline Hole & $F_{(1,19)}=45.40$ & $P<0.001$ & $F_{(1,19)}=31.08$ & $P<0.001$ \\
\hline Group $\times$ hole & $F_{(1,19)}=11.03$ & $P<0.01$ & $F_{(1,19)}=9.47$ & $P<0.01$ \\
\hline
\end{tabular}

$(P<0.05)$, and basal levels were recovered on sessions 13 $(P<0.05)$ and $14 \quad(P<0.05)$. No significant differences between sessions 8 (AM630, $1 \mathrm{mg} / \mathrm{kg}$, i.p.) and 12 (AM630, $3 \mathrm{mg} / \mathrm{kg}$, i.p.) were found. In the vehicle group, one-way repeated measures ANOVA in active nose pokes from session 7 to session 14 revealed no significant effects of session $\left(\mathrm{F}_{7,42}=1.46\right.$, NS) (Supplementary Figure 3).

\section{Gene Expression Analyses of TH and $\alpha 3-$ and $\alpha 4-n A C h R s$ between CB2KO and WT mice in VTA}

Real-time PCR analyses showed that TH mRNA levels were significantly reduced in VTA of CB2KO mice compared with WT mice (Figure 3a, Student's $t$-test, $t=-3.090, P=0.006$, $\mathrm{df}=18)$. On the other hand, the evaluation of nAChR gene expression revealed that there was a downregulation of $\alpha 3$ nAChRs (Figure 3b, Student's $t$-test, $t=2.726, P=0.016$, $\mathrm{df}=18$ ) and $\alpha 4$-nAChRs (Figure $3 \mathrm{c}$, Student's $t$-test, $t=3.269, P=0.005, \mathrm{df}=18)$ in VTA of CB2KO mice.

\section{Double Immunostaining with CB2r/ $\alpha 3-n A C h R s$ and CB2r/ $\alpha 4-n A C h R s$ in NAcc and VTA Cells}

In WT mice, double-immunolabeled cells with $\mathrm{CB} 2 \mathrm{r} / \alpha 3$ nAChR (Figure $4 \mathrm{aA}-\mathrm{bC}$ ) and CB2r/ $\alpha 4-\mathrm{nAChR}$ (Figure $4 \mathrm{cA}-$ $\mathrm{dC})$ antibodies were seen in several brain regions and, in particular, in NAcc and VTA. As in previous studies where different brain regions were analyzed (Aracil-Fernandez et al, 2012; Onaivi et al, 2008a), CB2r immunolabeling was mostly found in the soma of neurons and in the soma and processes of glial cells (Supplementary Figure 1). The $\alpha 3-\mathrm{nAChR}$ immunolabeling was much widely distributed in the cytoplasm of immunolabeled cells (mostly neurons; Figure 4aB). In the neocortex, $\alpha 3-n A C h R$ Ab labeled long apical dendrite segments of pyramidal neurons (Supplementary Figure 2). In contrast, $\alpha 4$-nAChR immunolabeling was mostly found in the cell bodies and occasionally in the proximal processes.

In NAcc, all $\alpha 3$-nAChR- and $\alpha 4$-nAChR-immunolabeled cells were $\mathrm{CB} 2 \mathrm{r}$ immunopositive (Figure $4 \mathrm{aC}$ and $\mathrm{bC}$ ). In VTA, scarce $\alpha 3$-nAChR- and $\alpha 4$-nAChR-immunolabeled cells were, however, CB2r immunonegative (arrow in Figure 4bB and arrowhead in Figure $4 \mathrm{~dB}$ ).

\section{Nicotine Withdrawal Syndrome Evaluation in WT and CB2KO Mice}

Mecamylamine-precipitated withdrawal syndrome in chronically nicotine-treated mice was evaluated in video recordings. The behavior of nicotine-treated $\mathrm{CB} 2 \mathrm{KO}$ mice did not significantly differ from saline-treated littermates, whereas
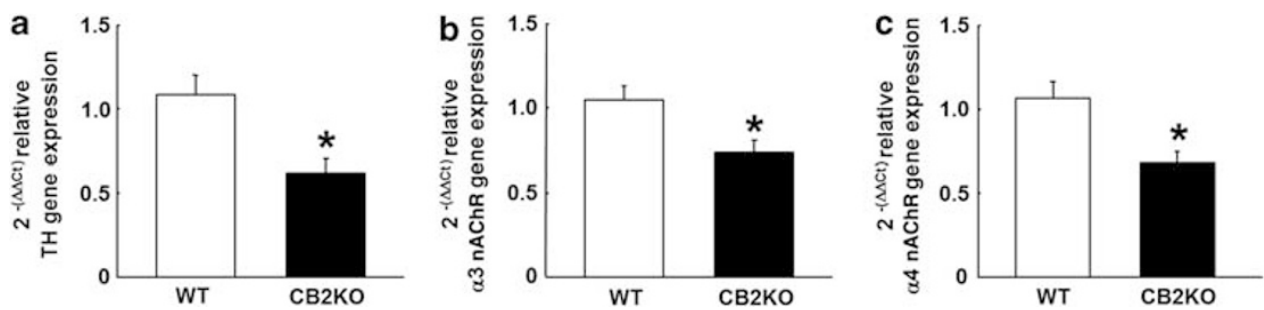

Figure 3 Real-time PCR studies of TH and $\alpha 3-n A C h R s / \alpha 4-n A C h R s$ in the VTA of WT mice. Evaluation of TH and $\alpha 3-$ and $\alpha 4-n A C h R$ gene expression in the VTA under baseline conditions. Columns represent the means and vertical lines \pm SEM of $2^{-}$( $\Delta \Delta \mathrm{ct}$ ) of relative TH (a), $\alpha 3-n A C h R$ (b), and $\alpha 4-n A C h R$ (c) gene expression in WT and CB2KO mice. *Represents values from CB2KO mice that are significantly different (Student's $t$-test, $P<0.05)$ from WT mice. 

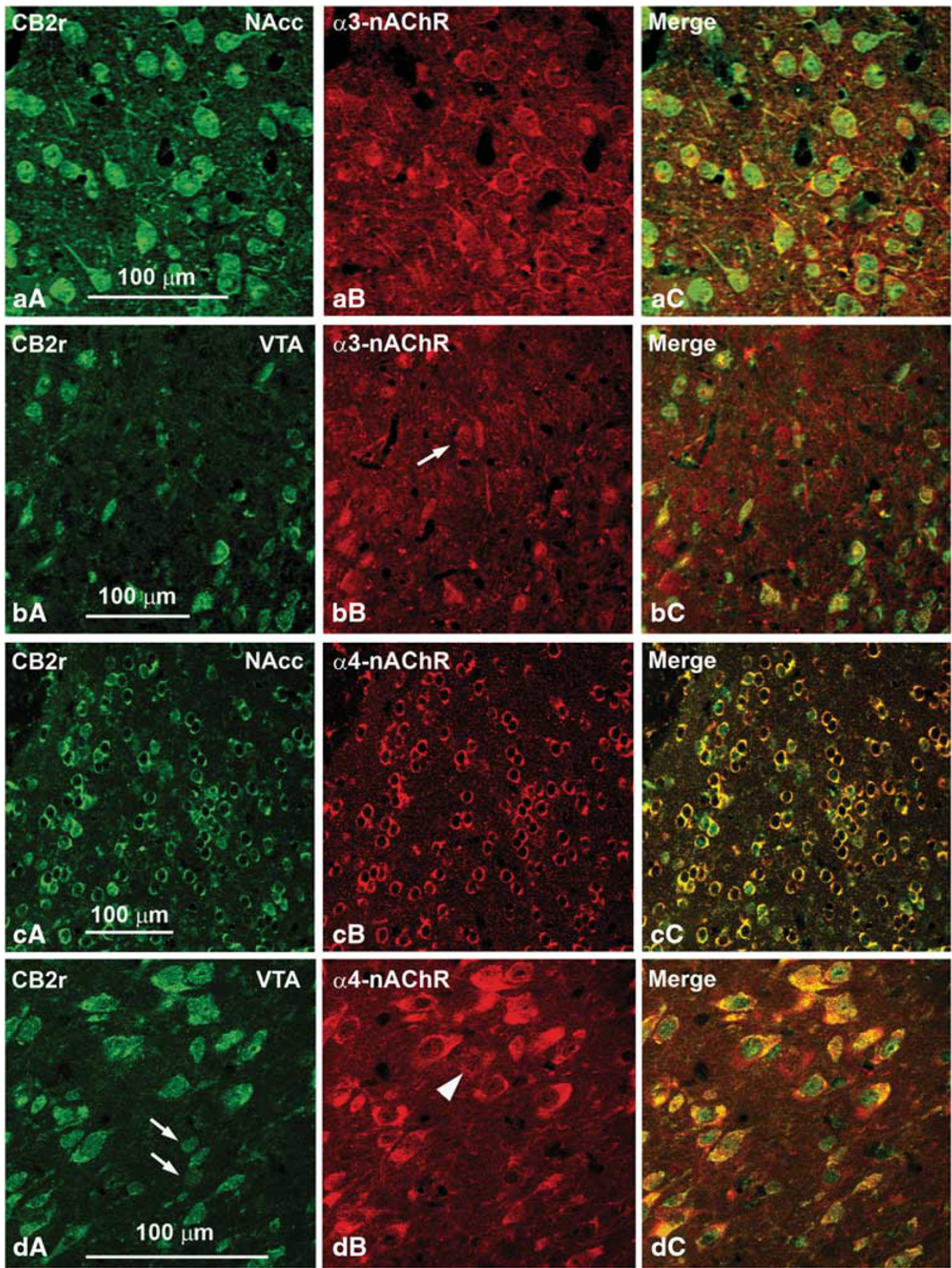

Figure 4 Immunolabeling for CB2r and $\alpha 3-n A C h R s / \alpha 4-n A C h R s$ in the NAcc and VTA of WT mice. Confocal photomicrographs showing immunolabeling for CB2r (green cells in panels aA, bA, cA, and dA) and either for $\alpha 3$-nAChRs (red cells in panels $\mathrm{aB}$ and bB) or for $\alpha 4-n A C h R s$ (red cells in panels cB and $\mathrm{dB}$ ) in NAcc and VTA of WT mice. In NAcc, double labeling (yellow cells in panels $\mathrm{aC}$ and $\mathrm{cC}$ ) indicates that $\alpha 3$ - and $\alpha 4-n A C h R s$ colocalize with CB2r immunoreactive cells. In VTA, scarce $\alpha 3$ - and $\alpha 4-n A C h R$ immunoreactive cells are not labeled for CB2r (arrow in panel bB and arrowhead in panel dB), Arrows in panel dA point two CB2r-labeled cells that are immunonegative for $\alpha 4$-nAChRs.

nicotine-treated WT mice showed a marked withdrawal syndrome compared with saline-treated WT mice (Figure 5). The somatic signs evaluated include the number of rearings (Figure 5a, two-way ANOVA, genotype: $\mathrm{F}_{1,39}=12.182$, $P=0.001$; treatment: $\mathrm{F}_{1,39}=11.179, P=0.002$; genotype $\times$ treatment interaction: $\mathrm{F}_{1,39}=19.579, P<0.001$ ), groomings (Figure 5b, two-way ANOVA, genotype: $\mathrm{F}_{1,39}=39.502$, $P<0.001$; treatment: $\mathrm{F}_{1,39}=7.942, P=0.008$; genotype $\times$ treatment interaction: $F_{1,39}=22.952, P<0.001$ ), scratches (Figure 5c, two-way ANOVA, genotype: $\mathrm{F}_{1,39}=45.715$, $P<0.001$; treatment: $F_{1,39}=44.367, P<0.001$; genotype $\times$ treatment interaction: $\mathrm{F}_{1,39}=54.352, P<0.001$ ), teeth chatter- ing (Figure 5d, two-way ANOVA, genotype: $\mathrm{F}_{1,39}=235.698$, $P<0.001$; treatment: $\mathrm{F}_{1,39}=175.402, P<0.001$; genotype $\times$ treatment interaction: $\left.\mathrm{F}_{1,39}=168.491, P<0.001\right)$, and body tremors (Figure 5e, two-way ANOVA, genotype: $\mathrm{F}_{1,39}=38.955, P<0.001$; treatment: $\mathrm{F}_{1,39}=46.015, P<0.001$; genotype $\times$ treatment interaction: $\mathrm{F}_{1,39}=32.482, P<0.001$ ).

\section{Pharmacologic Regulation of Nicotine Withdrawal with AM630}

The effects of CB2r acute blockade on nicotine withdrawal syndrome were evaluated in WT mice by the administration 


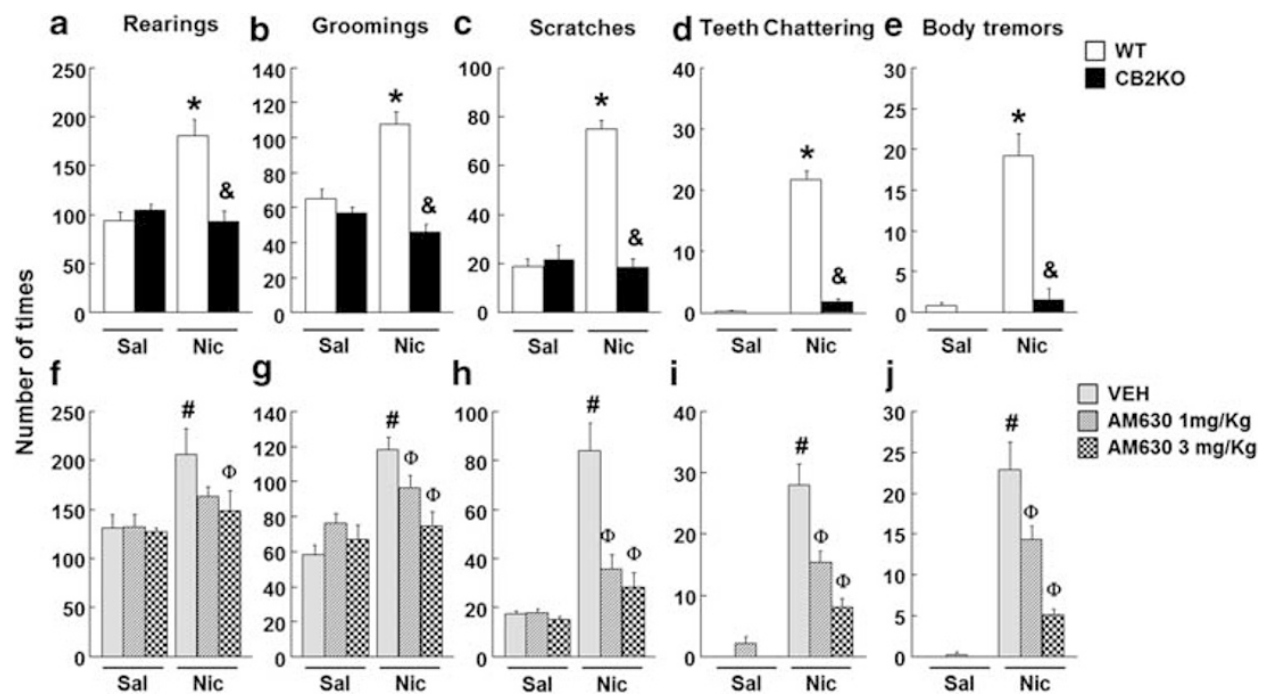

Figure 5 Somatic signs of mecamylamine-precipitated nicotine withdrawal in WT and CB2KO or WT mice treated with AM630. Columns represent the means and vertical lines \pm SEM of number of rearings $(a, f)$, groomings $(b, g)$, scratches $(c, h)$, teeth chattering $(d, i)$, and body tremors (e, h). *Values from WT nicotine-treated mice that are significantly different from WT saline-treated mice $(P<0.05){ }^{2}{ }^{2}$ alues from CB2KO nicotine-treated mice that are significantly different from WT nicotine-treated mice. "Values from WT nicotine- and vehicle-treated mice that are significantly different from WT saline- and vehicle-treated mice $(P<0.05) .{ }^{\Phi}$ Values from WT nicotine- and AM630-treated mice that are significantly different from WT nicotine- and vehicle-treated mice $(P<0.05)$.

of AM630. Mecamylamine-precipitated withdrawal was significantly higher in the nicotine-vehicle group in comparison with saline-vehicle group $(P<0.001)$. On the other hand, AM630 treatment did not produce any significant change in saline-treated animals $(P>0.05)$, whereas AM630 significantly reduced the number of rearings (Figure $5 f$, two-way ANOVA, genotype: $\mathrm{F}_{1,59}=8.779, \quad P=0.005$; treatment: $\mathrm{F}_{2,59}=1.708, \quad P=0.192 ;$ genotype $\times$ treatment interaction: $\mathrm{F}_{2,59}=1.383, P=0.261$ ), groomings (Figure $5 \mathrm{~g}$, two-way ANOVA, genotype: $\mathrm{F}_{1,59}=25.425, \quad P<0.001$; treatment: $\mathrm{F}_{2,59}=3.773, \quad P=0.030 ;$ genotype $\times$ treatment interaction: $\mathrm{F}_{2,59}=7.811, \quad P=0.001$ ), scratches (Figure 5h, two-way ANOVA, genotype: $\mathrm{F}_{1,59}=45.121, \quad P<0.001$; treatment: $\mathrm{F}_{2,59}=14.328, \quad P<0.001$; genotype $\times$ treatment interaction: $\mathrm{F}_{2,59}=12.768, P<0.001$ ), teeth chattering (Figure 5i, twoway ANOVA, genotype: $\mathrm{F}_{1,59}=133.631, P<0.001$; treatment: $\mathrm{F}_{2,59}=17.270, \quad P<0.001$; genotype $\times$ treatment interaction: $\mathrm{F}_{2,59}=18.501, P<0.001$ ), and body tremors (Figure $5 \mathrm{j}$, twoway ANOVA, genotype: $\mathrm{F}_{1,59}=120.028, P<0.001$; treatment: $\mathrm{F}_{2,59}=17.020, P<0.001$; genotype $\times$ treatment interaction: $\left.\mathrm{F}_{2,59}=17.002, P<0.001\right)$.

\section{DISCUSSION}

This study provides the first evidence about the role of $\mathrm{CB} 2 \mathrm{r}$ in the rewarding, reinforcing, motivational, and physical effects induced by nicotine administration. This assumption is supported by the following observations: (1) deletion of CB2r or pharmacological blockade with AM630 inhibited the rewarding effects of nicotine in the CPP, (2) nicotine self-administration was attenuated in CB2KO mice or WT mice treated with AM630, (3) deletion of CB2r reduced TH, $\alpha 3-n A C h R$, and $\alpha 4-n A C h R$ gene expression in VTA, (4) CB2r colocalization with $\alpha 3$ - and $\alpha 4$-nAChRs both in NAcc and VTA, and (5) the somatic signs of nicotine withdrawal were significantly reduced in $\mathrm{CB} 2 \mathrm{KO}$ mice or WT mice treated with AM630.

Previous studies suggest a relevant role of CB2r on opiates, cocaine, and ethanol addiction behavior (Adamczyk et al, 2012; Aracil-Fernandez et al, 2012; Onaivi et al, 2008b). To explore the role of CB2r in the rewarding properties of nicotine, $\mathrm{CB} 2 \mathrm{KO}$ mice were exposed to the CPP following an unbiased procedure. Nicotine induced a reliable preference in WT mice, in agreement with previous results (Jackson et al, 2012), whereas no CPP was obtained in CB2KO mice at any of the nicotine doses used. In addition, a lower percentage of acquisition of intravenous nicotine self-administration was observed in CB2KO mice. The deficits in nicotine self-administration observed in CB2KO mice are not due to possible unspecific learning or motor deficits produced by the lacking of CB2r as both genotypes similarly acquired and maintained stable operant responding for water (unpublished data).

To further explore the role of CB2r in mediating nicotine actions, pharmacological studies employing the selective CB2r antagonist AM630 were performed in WT mice. AM630 blocked nicotine-induced CPP with the highest dose $(3 \mathrm{mg} / \mathrm{kg})$ and significantly reduced nicotine self-administration at FR1 (1 and $3 \mathrm{mg} / \mathrm{kg})$ and PR $(3 \mathrm{mg} / \mathrm{kg})$ schedules.

It is possible that the blockade of nicotine CPP could be produced by the aversive properties of AM630 $(3 \mathrm{mg} / \mathrm{kg})$ in saline-treated mice. It is also important to consider that the action of AM630 may depend on the state of the endocannabinoid tone that should be different between nicotine- and saline-treated mice. Further studies are needed to determine the precise molecular action of AM630 in these two different conditions.

Taken together, the present results revealed that the deletion or the pharmacological blockade of CB2r reduced the rewarding, reinforcing, and motivational properties of nicotine. However, these results are in contrast with those 
reported by Gamaleddin et al (2012), in which the administration of AM630 did not produce any significant effect on nicotine-reinforcing properties. The discrepancies between the two studies may be due, at least in part, to the following different experimental conditions: (1) these authors studied the effects of AM630 in long Evans rats instead of in CD1 mice; (2) the nicotine self-administration protocol used by Gamaleddin et al, (2012) also differs from that used in the present study, for instance they evaluated AM630 effects under FR5, PR, and reinstatement; instead of under FR1 and PR schedules; and (3) the doses of AM630 employed by them $(1.25,2.5$, and $5 \mathrm{mg} / \mathrm{kg})$ were slightly different from that used in the present study ( 1 and $3 \mathrm{mg} / \mathrm{kg}$ ). On the other hand, the results obtained in the present study are opposite in comparison with those found with cocaine motor sensitization, $\mathrm{CPP}$, and self-administration in mice overexpressing CB2r (Aracil-Fernandez et al, 2012) or with the administration of CB2r agonists (Xi et al, 2011). This could be explained by the different brain effects between both drugs as nicotine reward properties are related with the activation of several nAChRs, whereas cocaine produces a blockade of the DA transporter. The different molecular mechanisms underlying the addictive properties of both drugs may justify, at least in part, why genetic and pharmacological manipulation of CB2r results in opposite effects between cocaine and nicotine actions.

The reduced behavioral expression occurring in CB2KO compared with WT mice after nicotine administration could be associated with functional alterations in different key elements regulating nicotine addiction. This drug exerts its reinforcement properties through the activation of nAChRs (Stolerman and Jarvis, 1995) expressed at high levels in the mesolimbic reward DA system (Champtiaux et al, 2003; Jones and Wonnacott, 2004; Pidoplichko et al, 1997). The activation of nAChRs by nicotine increases DA release and TH expression in VTA (Liu et al, 2012; Rahman et al, 2003). These molecular changes in DA signaling are crucial for the development of nicotine dependence (David et al, 2006; Ferrari et al, 2002; Ikemoto et al, 2006; Laviolette and van der Kooy, 2004; Rahman et al, 2003). Intra-VTA infusion of nicotine receptor antagonists blocked the effect of systemic nicotine injections on DA release in NAcc (Nisell et al, 1994) and disrupt nicotine self-administration (Corrigall et al, 1994). Several evidences suggested that nicotine receptors containing the $\alpha 3$ - and $\alpha 4-n A C h R s$ are involved in the reinforcement effects of nicotine (Glick et al, 2011; Liu et al, 2012; Pons et al, 2008). Considering the key role of nAChRs mediating the rewarding effects of nicotine, it is tempting to speculate that the lack of nicotine reinforcement properties observed in CB2KO may be related to functional alterations occurring in nAChRs. Interestingly, $\alpha 3$ - and $\alpha 4-\mathrm{nAChR}$ gene expression was significantly reduced in the VTA of CB2KO. In addition, these alterations were accompanied by a significant reduction of TH gene expression in the VTA of CB2KO mice. This fact may explain, at least in part, the lack of nicotine-reinforcing effects and the impairment in the acquisition of nicotine self-administration and CPP observed in CB2KO mice. The results of this study also revealed that $\mathrm{CB} 2 \mathrm{r}$ are found in neurons and glial cells (mostly astrocytes) of WT mice. In addition, in NAcc and VTA of WT mice, almost all $\alpha 3-n A C h R-$ and $\alpha 4-n A C h R-$ immunolabeled cells were also CB2r immunopositive, which strongly suggest that CB2r and both $\alpha 3$ - and $\alpha 4$-nAChRs are located in the same neurons. There is no information available regarding the functional cooperation between the

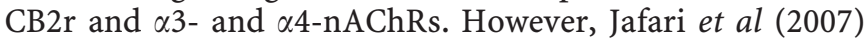
revealed that the activation or blockade of nAChRs modulates the analgesic effect induced by the selective CB2r agonist JWH133. Taken together, these results may provide a possible cellular mechanism to understand the important cooperative role of $\alpha 3$ - and $\alpha 4-n A C h R s$ and CB2r in the behavioral responses associated with the acquisition of nicotine-seeking behavior. Nevertheless, functional alterations in additional key elements closely related with the reward system, such as GABA and/or glutamate, may contribute to the low nicotine sensitivity phenotype observed in CB2KO mice. Additional studies are needed to explain the exact nature of the interaction between the CB2r and the nAChRs and the molecular mechanisms responsible of these functional alterations in $\mathrm{CB} 2 \mathrm{KO}$ mice.

The role of CB2r in the development of withdrawal signs was also evaluated. The experimental design used to precipitate a nicotine withdrawal syndrome was previously reported by others (Biala and Weglinska, 2005; Damaj et al, 2003; Plaza-Zabala et al, 2012; Stoker et al, 2008). In this study, the administration of mecamylamine in WT mice significantly increased the most prominent somatic signs observed during nicotine withdrawal (rearings, groomings, scratches, teeth chattering, and body tremors). Interestingly, the lack of CB2r completely blocked the somatic expression of the nicotine withdrawal syndrome. To further evaluate whether the CB2r is specifically involved in the regulation of nicotine withdrawal syndrome, the effects of AM630 were examined in the same experimental design in WT mice. Indeed, the acute administration of AM630 significantly attenuated the somatic expression of nicotine withdrawal syndrome, obtaining a behavioral response similar to that observed in CB2KO mice.

In conclusion, the results presented here revealed that $\mathrm{CB} 2 \mathrm{r}$ plays a pivotal role in the regulation of the rewarding and reinforcing effects of nicotine and in the behavioral expression of the nicotine withdrawal syndrome. The lack or pharmacological blockade of CB2r resulted in impairments in the CPP, the acquisition of nicotine selfadministration, and nicotine withdrawal syndrome. Changes in TH, $\alpha 3-n A C h R$ and $\alpha 4-n A C h R$ gene expression were found in VTA of CB2KO mice that may be involved, at least in part, in the distinct behavioral responses to nicotine. In addition, the results pointed out that pharmacological manipulation of the CB2r deserves further consideration as a potential new valuable target for the treatment of nicotine dependence. Further studies are needed to explore this hypothesis.

\section{FUNDING AND DISCLOSURE}

This study was supported by the following research grants: Ministerio de Ciencia e Innovación (SAF2011-23420 to Jorge Manzanares, SAF2009-10689 to Pere Berbel, and SAF201129864 to Rafael Maldonado); Ministerio de Economía y Competitividad, Dirección General de Investigación (PSI2011-24762) to José Miñarro; Generalidad Valenciana, Consejería de Educación (PROMETEO/2009/072) to José 
Miñarro; Gobierno Catalán (SGR2009-00131) to Rafael Maldonado; ICREA Academia-2008 to Rafael Maldonado; and Instituto de Salud 'Carlos III' (FIS), RETICS, Red de Trastornos Adictivos (RD06/0001/1004, RD12/0028/0019 to Jorge Manzanares; RD06/001/0016, RD12/0028/005 to José Miñarro; RD06/001/001, RD12/0028/0023 to Rafael Maldonado). The authors declare no conflict of interest.

\section{ACKNOWLEDGEMENTS}

We thank Patricia Rodríguez, Analía Rico, and Roberto Cabrera for invaluable technical assistance and collaboration.

\section{REFERENCES}

Adamczyk P, Miszkiel J, McCreary AC, Filip M, Papp M, Przegalinski E (2012). The effects of cannabinoid CB1, CB2 and vanilloid TRPV1 receptor antagonists on cocaine addictive behavior in rats. Brain Res 1444: 45-54.

Aracil-Fernandez A, Trigo JM, Garcia-Gutierrez MS, Ortega-Alvaro A, Ternianov A, Navarro D et al (2012). Decreased cocaine motor sensitization and self-administration in mice overexpressing cannabinoid $\mathrm{CB}(2)$ receptors. Neuropsychopharmacology 37: 1749-1763.

Balerio GN, Aso E, Berrendero F, Murtra P, Maldonado R (2004). Delta9-tetrahydrocannabinol decreases somatic and motivational manifestations of nicotine withdrawal in mice. Eur $J$ Neurosci 20: 2737-2748.

Benowitz NL (2010). Nicotine addiction. New Engl J Med 362: 2295-2303.

Benowitz NL, Fitzgerald GA, Wilson M, Zhang Q (1993). Nicotine effects on eicosanoid formation and hemostatic function: comparison of transdermal nicotine and cigarette smoking. J Am Coll Cardiol 22: 1159-1167.

Biala G, Weglinska B (2005). Blockade of the expression of mecamylamine-precipitated nicotine withdrawal by calcium channel antagonists. Pharmacol Res 51: 483-488.

Burokas A, Gutierrez-Cuesta J, Martin-Garcia E, Maldonado R (2012). Operant model of frustrated expected reward in mice. Addict Biol 17: 770-782.

Castane A, Berrendero F, Maldonado R (2005). The role of the cannabinoid system in nicotine addiction. Pharmacol Biochem Behav 81: 381-386.

Castane A, Valjent E, Ledent C, Parmentier M, Maldonado R, Valverde O (2002). Lack of CB1 cannabinoid receptors modifies nicotine behavioural responses, but not nicotine abstinence. Neuropharmacology 43: 857-867.

Champtiaux N, Gotti C, Cordero-Erausquin M, David DJ, Przybylski C, Lena C et al (2003). Subunit composition of functional nicotinic receptors in dopaminergic neurons investigated with knock-out mice. J Neurosci 23: 7820-7829.

Cohen C, Perrault G, Voltz C, Steinberg R, Soubrie P (2002). SR141716, a central cannabinoid $(\mathrm{CB}(1))$ receptor antagonist, blocks the motivational and dopamine-releasing effects of nicotine in rats. Behav Pharmacol 13: 451-463.

Corrigall WA, Coen KM, Adamson KL (1994). Self-administered nicotine activates the mesolimbic dopamine system through the ventral tegmental area. Brain Res 653: 278-284.

Cossu G, Ledent C, Fattore L, Imperato A, Bohme GA, Parmentier $\mathrm{M}$ et al (2001). Cannabinoid CB1 receptor knockout mice fail to self-administer morphine but not other drugs of abuse. Behav Brain Res 118: 61-65.

Damaj MI, Kao W, Martin BR (2003). Characterization of spontaneous and precipitated nicotine withdrawal in the mouse. J Pharmacol Exp Ther 307: 526-534.
David V, Besson M, Changeux JP, Granon S, Cazala P (2006). Reinforcing effects of nicotine microinjections into the ventral tegmental area of mice: dependence on cholinergic nicotinic and dopaminergic D1 receptors. Neuropharmacology 50: $1030-1040$.

Dwoskin LP, Rauhut AS, King-Pospisil KA, Bardo MT (2006). Review of the pharmacology and clinical profile of bupropion, an antidepressant and tobacco use cessation agent. CNS Drug Rev 12: 178-207.

Ferrari R, Le Novere N, Picciotto MR, Changeux JP, Zoli M (2002). Acute and long-term changes in the mesolimbic dopamine pathway after systemic or local single nicotine injections. Eur J Neurosci 15: 1810-1818.

Gamaleddin I, Zvonok A, Makriyannis A, Goldberg SR, Le Foll B (2012). Effects of a selective cannabinoid CB2 agonist and antagonist on intravenous nicotine self administration and reinstatement of nicotine seeking. PLoS One 7: e29900.

Glick SD, Sell EM, McCallum SE, Maisonneuve IM (2011). Brain regions mediating alpha3beta4 nicotinic antagonist effects of 18MC on nicotine self-administration. Eur J Pharmacol 669: 71-75.

Hays JT, Ebbert JO (2010). Adverse effects and tolerability of medications for the treatment of tobacco use and dependence. Drugs 70: 2357-2372.

Ikemoto S, Qin M, Liu ZH (2006). Primary reinforcing effects of nicotine are triggered from multiple regions both inside and outside the ventral tegmental area. J Neurosci 26: 723-730.

Ishiguro H, Iwasaki S, Teasenfitz L, Higuchi S, Horiuchi Y, Saito T et al (2007). Involvement of cannabinoid CB2 receptor in alcohol preference in mice and alcoholism in humans. Pharmacogenomics J 7: 380-385.

Jackson KJ, McLaughlin JP, Carroll FI, Damaj MI (2012). Effects of the kappa opioid receptor antagonist, norbinaltorphimine, on stress and drug-induced reinstatement of nicotine-conditioned place preference in mice. Psychopharmacology (Berl) 226: 763-768.

Jafari MR, Golmohammadi S, Ghiasvand F, Zarrindast MR, Djahanguiri B (2007). Influence of nicotinic receptor modulators on CB2 cannabinoid receptor agonist (JWH133)-induced antinociception in mice. Behav Pharmacol 18: 691-697.

Jones IW, Wonnacott S (2004). Precise localization of alpha7 nicotinic acetylcholine receptors on glutamatergic axon terminals in the rat ventral tegmental area. J Neurosci 24: 11244-11252.

Laviolette SR, van der Kooy D (2004). The neurobiology of nicotine addiction: bridging the gap from molecules to behaviour. Nat Rev Neurosci 5: 55-65.

Le Foll B, Goldberg SR (2004). Rimonabant, a CB1 antagonist, blocks nicotine-conditioned place preferences. Neuroreport 15: 2139-2143.

Liu L, Zhao-Shea R, McIntosh JM, Gardner PD, Tapper AR (2012). Nicotine persistently activates ventral tegmental area dopaminergic neurons via nicotinic acetylcholine receptors containing alpha4 and alpha6 subunits. Mol Pharmacol 81: 541-548.

Livak KJ, Schmittgen TD (2001). Analysis of relative gene expression data using real-time quantitative PCR and the 2(-Delta Delta C(T)) method. Methods 25: 402-408.

Martin-Garcia E, Barbano MF, Galeote L, Maldonado R (2009). New operant model of nicotine-seeking behaviour in mice. Int $J$ Neuropsychopharmacol 12: 343-356.

Merritt LL, Martin BR, Walters C, Lichtman AH, Damaj MI (2008). The endogenous cannabinoid system modulates nicotine reward and dependence. J Pharmacol Exp Ther 326: 483-492.

Mihalak KB, Carroll FI, Luetje CW (2006). Varenicline is a partial agonist at alpha4beta2 and a full agonist at alpha7 neuronal nicotinic receptors. Mol Pharmacol 70: 801-805.

Navarrete F, Perez-Ortiz JM, Manzanares J (2012). Cannabinoid $\mathrm{CB}(2)$ receptor-mediated regulation of impulsive-like behaviour in DBA/2 mice. Br J Pharmacol 165: 260-273. 
Nisell M, Nomikos GG, Svensson TH (1994). Systemic nicotineinduced dopamine release in the rat nucleus accumbens is regulated by nicotinic receptors in the ventral tegmental area. Synapse 16: 36-44.

Onaivi ES, Ishiguro H, Gong JP, Patel S, Meozzi PA, Myers L et al (2008a). Brain neuronal CB2 cannabinoid receptors in drug abuse and depression: from mice to human subjects. PLoS One 3: e1640.

Onaivi ES, Ishiguro H, Gong JP, Patel S, Meozzi PA, Myers L et al (2008b). Functional expression of brain neuronal CB2 cannabinoid receptors are involved in the effects of drugs of abuse and in depression. Ann N Y Acad Sci 1139: 434-449.

Palkovits M (1983). Punch sampling biopsy technique. Methods Enzymol 103: 368-376.

Paxinos G, Franklin KBJ (2001). The mouse brain in stereotaxic coordinates Academic Press. Harcourt Science and Technology Company: New York.

Pidoplichko VI, DeBiasi M, Williams JT, Dani JA (1997). Nicotine activates and desensitizes midbrain dopamine neurons. Nature 390: 401-404.

Plaza-Zabala A, Flores A, Maldonado R, Berrendero F (2012). Hypocretin/orexin signaling in the hypothalamic paraventricular nucleus is essential for the expression of nicotine withdrawal. Biol Psychiatry 71: 214-223.

Pons S, Fattore L, Cossu G, Tolu S, Porcu E, McIntosh JM et al (2008). Crucial role of alpha4 and alpha6 nicotinic acetylcholine receptor subunits from ventral tegmental area in systemic nicotine self-administration. J Neurosci 28: 12318-12327.
Rahman S, Zhang J, Corrigall WA (2003). Effects of acute and chronic nicotine on somatodendritic dopamine release of the rat ventral tegmental area: in vivo microdialysis study. Neurosci Lett 348: 61-64.

Salas R, Pieri F, De Biasi M (2004). Decreased signs of nicotine withdrawal in mice null for the beta4 nicotinic acetylcholine receptor subunit. J Neurosci 24: 10035-10039.

Soria G, Barbano MF, Maldonado R, Valverde O (2008). A reliable method to study cue-, priming-, and stress-induced reinstatement of cocaine self-administration in mice. Psychopharmacology (Berl) 199: 593-603.

Soria G, Mendizabal V, Tourino C, Robledo P, Ledent C, Parmentier $\mathrm{M}$ et al (2005). Lack of CB1 cannabinoid receptor impairs cocaine self-administration. Neuropsychopharmacology 30: $1670-1680$.

Stoker AK, Semenova S, Markou A (2008). Affective and somatic aspects of spontaneous and precipitated nicotine withdrawal in C57BL/6J and BALB/cByJ mice. Neuropharmacology 54: 1223-1232.

Stolerman IP, Jarvis MJ (1995). The scientific case that nicotine is addictive. Psychopharmacology (Berl) 117: 2-10 Discussion 14-20.

Valjent E, Mitchell JM, Besson MJ, Caboche J, Maldonado R (2002). Behavioural and biochemical evidence for interactions between Delta 9-tetrahydrocannabinol and nicotine. Br J Pharmacol 135: 564-578.

Xi ZX, Peng XQ, Li X, Song R, Zhang HY, Liu QR et al (2011). Brain cannabinoid CB receptors modulate cocaine's actions in mice. Nat Neurosci 14: 1160-1166.

Supplementary Information accompanies the paper on the Neuropsychopharmacology website (http://www.nature.com/npp). 